\title{
How heterogeneous are MSM from Brazilian cities? An analysis of sexual behavior and perceived risk and a description of trends in awareness and willingness to use pre-exposure prophylaxis
}

\author{
Thiago S. Torres ${ }^{*}$ (D), Luana M. S. Marins, Valdilea G. Veloso, Beatriz Grinsztejn and Paula M. Luz
}

\begin{abstract}
Background: Brazil has the largest population of individuals living with HIV/AIDS in Latin America, with a disproportional prevalence of infection among gays, bisexuals and other men who have sex with men (MSM). Of relevance to prevention and treatment efforts, Brazilian MSM from different regions may differ in behaviors and risk perception related to HIV.

Methods: We report on MSM living in 29 different cities: 26 Brazilian state capitals, the Federal District and two large cities in São Paulo state assessed in three web-based surveys (2016-2018) advertised on Grindr, Hornet and Facebook. Using logistic regression models, we assessed the association of risk behavior with HIV perceived risk as well as factors associated with high-risk behavior.

Results: A total of 16,667 MSM completed the survey. Overall, MSM from the North and Northeast were younger, more black/mixed-black, of lower income and lower education compared to MSM from the South, Southeast and Central-west. Though 17\% had never tested for HIV (with higher percentages in the North and Northeast), condomless receptive anal sex (previous 6 months) and high-risk behavior as per HIV Incidence Risk scale for MSM were observed for 41 and 64\%, respectively. Sexual behavior and HIV perceived risk had low variability by city and high-risk behavior was strongly associated with high HIV perceived risk. Younger age, being gay/homosexual, having a steady partner, binge drinking, report of sexually transmitted infection (STI) and ever testing for HIV were associated with increased odds of high-risk behavior. Awareness and willingness to use PrEP increased from 2016 to 2018 in most cities.

Conclusions: Overall, MSM socio-demographic characteristics were heterogeneous among Brazilian cities, but similarities were noted among the cities from the same administrative region with a marked exception of the Federal District not following the patterns for the Central-West. Combination HIV prevention is most needed among young men who self-identify as gay/homosexual, report binge drinking or prior STI.
\end{abstract}

Keywords: MSM, HIV risk behavior, HIV perceived risk, Web-based survey, PrEP, Brazil, Latin America

\footnotetext{
* Correspondence: thiago.torres@ini.fiocruz.br

Fundação Oswaldo Cruz, Instituto Nacional de Infectologia Evandro Chagas,

Av. Brasil 4365, Manguinhos, Rio de Janeiro 21040-900, Brazil
}

(c) The Author(s). 2019 Open Access This article is distributed under the terms of the Creative Commons Attribution 4.0 International License (http://creativecommons.org/licenses/by/4.0/), which permits unrestricted use, distribution, and reproduction in any medium, provided you give appropriate credit to the original author(s) and the source, provide a link to the Creative Commons license, and indicate if changes were made. The Creative Commons Public Domain Dedication waiver (http://creativecommons.org/publicdomain/zero/1.0/) applies to the data made available in this article, unless otherwise stated. 


\section{Background}

Brazil is the largest country in Latin America and the fifth largest country by area and population, with more than 212 million inhabitants [1]. Brazil is divided into five geographic regions: North (7 states), Northeast (9 states), Central-west (3 states and the Federal District), Southeast (4 states) and South (3 states). The Southeast, where São Paulo and Rio de Janeiro are located, is the most populous and industrialized region accounting for $42 \%$ of all Brazilians and almost $50 \%$ of the country's gross domestic product (GDP). Brazilian geographic regions have impressive disparities in terms of GDP per capita: the Northeast and North have the lowest values (USD 4000-5000) while GDP per capita in the Centralwest, South and Southeast ranges from USD 9000 to 10, 000. Disparities in the human development index (HDI) are also observed: while HDI ranges from 0.850 to 0.766 in the states of Central-west, South and Southeast, it varies from 0.752 to 0.683 in the North and Northeast. Furthermore, disparities exist within regions and cities, as a result of the dramatic inequalities in wealth and health. In Rio de Janeiro city, for example, the human development index (HDI) varies from very high to low in two neighbor areas: Gávea (0.970) and Rocinha (0.732) [2].

Brazil has the largest population of individuals living with HIV/AIDS in Latin America, with a disproportional prevalence of infection among men who have sex with men (MSM) [3, 4]. A respondent driven sampling (RDS) study of HIV prevalence found that $18.4 \%$ of MSM in Brazil were living with HIV in 2016 [5], higher than the previous RDS study conducted in 2009 (14.2\%) [6]. In 2017, approximately 50\% of reported HIV infections among male were attributed to male-to-male sexual contact [7], even though a national survey has showed that approximately $3.5 \%$ (95\% confidence interval [CI] 2.94.3\%) of the Brazilian men between 15 and 64 years old reported sex with other men [8]. Unfortunately, new infections in this population continue to rise [7]. To stop the HIV epidemic in Brazil, a continental, diverse and unequal country, it is necessary to understand and verify how heterogeneous are MSM from each region are in terms of sexual behavior and risk perception.

Since December 2017, pre-exposure prophylaxis (PrEP) with emtricitabine and tenofovir disoproxil fumarate (FTC/TDF) is offered free of charge through the Brazilian Public Health System (SUS) to populations at substantial risk for HIV infection including eligible MSM within the HIV prevention package [9]. During 2018, the first year of PrEP provision in SUS, PrEP uptake among eligible MSM varied considerably from a maximum of $25 \%$ in Florianopolis (in the South) to a low of $1 \%$ in Belém (in the North) [4]. One explanation for such a discrepancy could be a lack of perceived risk that differentially impacts PrEP uptake throughout the country. Data on sexual behavior, risk perception and willingness to use PrEP among MSM from each Brazilian region is essential to support the implementation and rollout of the PrEP program.

This study provides an analysis of sexual behavior and perceived risk, as well as a description of socio-demographic characteristics and trends in awareness and willingness to use PrEP among MSM living in all Brazilian state capitals, the Federal District and two large cities from São Paulo state (Campinas and Santos).

\section{Methods \\ Study design}

We conducted three cross-sectional web-based studies targeting MSM in Brazil from 2016 to 2018, one per year. Individuals who met eligibility criteria (age $\geq 18$ years, cisgender men, and HIV uninfected self-report) and who acknowledged reading the informed consent text were directed to the online questionnaire, which was programmed on SurveyGizmo ${ }^{\circ}$. The first study (2016 survey) was conducted in July 2016 in 10 Brazilian capitals, two from each Brazilian Geographical Region: Belém and Manaus (North); Salvador and Recife (Northeast); Brasília and Goiânia (Central-West); Florianópolis and Porto Alegre (South); and Rio de Janeiro and São Paulo (Southeast) [10]. The second (2017 survey) [11] and third (2018 survey) [12] studies were conducted in July 2017 and March to April 2018, respectively, and were expanded to all Brazilian state capitals and two large urban centers in São Paulo State (Santos and Campinas). The 2016 and 2018 surveys were advertised on two geosocial networking (GSN) apps for sexual encounters among MSM: Hornet and Grindr. The 2018 survey was also advertised on Facebook social media. The 2017 survey was advertised on Hornet only. No incentives were provided for answering the survey and, on average, participants took approximately 10 mins to complete it.

\section{Survey instrument}

The survey instrument was composed of five sections (25 questions) addressing: sociodemographic information, substance use, sexual behavior and history of sexually transmitted infections, HIV perceived risk and use of HIV testing as well as awareness and willingness to use PrEP (Additional file 1). Though the instrument was not the same in the three surveys, the items used in this analysis were the present in all.

\section{Variables \\ Socio-demographic}

Age at the time of the survey was categorized in 4 brackets: 18 to $24 ; 25$ to $29 ; 30$ to 34 and $\geq 35$ years; race was categorized in white/Asian, black and pardo (mixed- 
race) /native; schooling was categorized in $<10$ years, $10-12$ years, $13-16$ years and $>16$ years. Family monthly income was grouped into the following strata: $\leq 1>1-3$, $>3-10$ and $>10$ minimum wages (Brazilian minimum wage was $\mathrm{R} \$ 998$ or US\$268 in January 2019). Sexual orientation was dichotomized in gay or homosexual and other (bisexual, heterosexual or other). Steady partner (male or female) was dichotomized in yes/no. To infer the size of the MSM community in each city, we used the most recent nation-wide survey of sexual practices and behavior that estimated that $3.5 \%$ of men between 15 and 64 years had sex with other men [8].

\section{Substance use}

Binge drinking [13] was evaluated with the question "In the last 6 months, did you drink 5 or more drinks in a couple of hours?". Use of stimulants (cocaine, poppers, crack, or amphetamines) during the previous 6 months was dichotomized in yes/no.

\section{Sexual behavior and sexually transmitted infections}

Sexual behavior in the last 6 months was assessed with the following questions: number of partners, condomless receptive anal sex, sex with $\mathrm{HIV}+$ partner and number of insertive anal intercourses with HIV+ partner. These questions (in addition to other questions regarding age and use of stimulants) compose the HIV Incidence Risk Index for MSM (HIRI-MSM), a 7-item questionnaire developed by Smith et al. [14] to predict HIV seroconversion among MSM that is recommended by the Centers for Disease Control and Prevention (CDC) to screen individuals who should be evaluated for PrEP use [15]. Scores $<10$ and $\geq 10$ were considered as "low risk" and "high risk", respectively $[14,15]$. Report of sexually transmitted infections (STI; syphilis, gonorrhea or rectal chlamydia) in the last 6 months were dichotomized in yes/no.

\section{HIV perceived risk and HIV testing}

HIV perceived risk was assessed with the question "In your opinion, what is your risk of getting HIV in the next year?" with five possible options: "No risk", "Low risk", "High risk/50\%", "Certain/100\%" and "I don't know or I don't want to answer", which was considered as a missing value for the analysis. We have described HIV perceived risk results in three groups: "No risk", "Low risk" and "High risk" which included the categories "High risk/50\%" and "Certain/100\%"). For the logistic models, "No risk" and "Low risk" were grouped into one category. Individuals were asked about previous HIV tests (never or at least once in lifetime). Additionally, among those who reported never having tested, we accessed their reasons with the question "Why have you never tested for HIV?" with the following possible responses: "I am not at risk of getting infected", "I don't think it is practical to go to a health care center", "I am ashamed", "I am afraid of getting a positive result", "I am too lazy" and "Other reasons".

\section{Awareness and willingness to use PrEP}

PrEP awareness was assessed with the question "Have you ever heard of PrEP?" (yes/no). Willingness to use PrEP was defined as the "High interest" option on a four-point Likert scale with the question "What level of interest would you have in using PrEP?". A brief explanation about PrEP was provided before these questions were asked. These questions have been previously used by our research team to describe PrEP awareness and willingness to use PrEP [10-12, 16].

\section{Statistical analysis}

Socio-demographic characteristics and substance use, sexual and preventive behaviors of the participants were described according to their hometown for each Brazilian State capital, the Federal District, and two major cities in São Paulo. The results were organized according to 1) Brazilian geographical regions, from North to South, and, within each region, 2) by cities with the greatest number of participants: North (Manaus, Belém, Porto Velho, Palmas, Boa Vista, Rio Branco and Macapá), Northeast (Recife, Salvador, Fortaleza, Natal, João Pessoa, Aracaju, Teresina, Maceió and São Luís), Central-west (Brasília, Goiânia, Cuiabá and Campo Grande), Southeast (São Paulo, Rio de Janeiro, Belo Horizonte, Campinas, Vitória and Santos) and South (Porto Alegre, Curitiba and Florianópolis). Reasons for never testing for HIV were presented according to the Brazilian geographical region. Using a logistic regression model, we tested the association between an individual's HIV perceived risk and their reported behavior as measured by: 1) the HIRI-MSM, 2) condomless receptive anal sex and 3) number of male partners. Following, we tested, for 11 cities, the hypothesis that sexual behavior as defined by the HIRI-MSM and by condomless receptive anal sex is associated with HIV risk perception using Pearson's chi-squared test. Finally, a logistic regression model was used to explore factors associated with high risk behavior as per HIRI-MSM. Models were developed for the whole country and for the two cities with the greatest number of participants within each region (except for the Southeast, the most populous region in Brazil, with 3 cities): North (Manaus and Belém), Northeast (Recife and Salvador), Central-west (Brasília and Goiânia), Southeast (São Paulo, Rio de Janeiro and Belo Horizonte that ranks third in number of participants in the present study) and South (Porto Alegre and Curitiba). Finally, trends in PrEP awareness and willingness from 2016 to 2018 were graphically provided for the overall sample (Brazil) and the 10 state capitals included 
in the three surveys: Belém, Brasília, Florianópolis, Goiânia, Manaus, Porto Alegre, Recife, Rio de Janeiro, Salvador and São Paulo. Analyses were performed using Software R (The R project www.r-project.org).

\section{Results}

A total of 16,667 MSM completed the survey: 5065 (30.4\%) in 2016, 2841 (17.0\%) in 2017 and 8761 (52.6\%) in 2018. Most participants were from the Southeast (10, $418 ; 62.5 \%)$, followed by Northeast $(2320 ; 13.9 \%)$, Central-west (1694; 10.2\%), South (1505; 9.0\%) and North $(730 ; 4.4 \%)$. The two largest Brazilian cities had the highest number of responders: São Paulo (34.6\%) and Rio de Janeiro (19.0\%) (Table 1). Considering the estimated MSM population of each city, Florianópolis was the city with the greatest proportion of responders (6.6\%), followed by São Paulo (4.2\%) and Rio de Janeiro (4.1\%).

Overall, median age was 29 years (IQR: 24-36). The age distribution of the participants was shifted towards younger MSM (18-24 years) in most of cities in the North, Northeast and Central-west regions, representing almost half of responders from Manaus (46.5\%) and Belém (43.1\%), the two largest urban areas in the North. In large cities from the Southeast, South and Brasília the proportion of older MSM (35+ years) was higher (31\% in São Paulo and Rio de Janeiro). Most responders from the North and Northeast self-declared pardo or native, and Salvador was the city with the greatest proportion of black MSM (30.7\%). Conversely, more than half of responders from the Central-west, Southeast and South selfreported as white, except in Cuiabá (35.9\%). Southern cities had the greatest proportion of white MSM (highest in Porto Alegre with $82.0 \%$ ), followed by the cities from São Paulo State (68.1\% in São Paulo city). Family monthly income was shifted towards lower income in cities in the North and Northeast with approximately $20 \%$ of responders earning one minimum wage in Manaus (19.2\%), Rio Branco (21.7\%), Aracaju (17.6\%), and Teresina (20\%). Most responders from the Central-west, Southeast and South regions had middle income ( $>3$ to 10 minimum wages), and the greatest proportion of MSM with higher income (> 10 minimum wages) was observed in Brasília (34.2\%), São Paulo (20.9\%) and Rio de Janeiro (18.7\%). Having > 12 years of schooling (equivalent to high school) was reported by more than half of the respondents in every city except for Manaus (45.8\%). Brasilia was the city with the greatest proportion of MSM with > 16 years of schooling (36.3\%).

Most participants self-declared as gay or homosexual (89.9\%) (Table 2). The proportion of MSM with a steady partner varied across the country, ranging in the largest urban areas from $19.5 \%$ in Belém to $28.2 \%$ in Brasília. Most MSM reported binge drinking (70.2\%) with only slight variability by region and use of stimulants was more prevalent in the South and Southeast $(\sim 20 \%)$, the highest proportions were observed in the cities from São Paulo state (24.1\% in São Paulo city), Brasília (23.1\%) and Florianópolis (22.9\%). Overall, 13.1\% of participants reported an STI, Florianópolis (18.6\%) had the highest proportion among the cities with $>300$ responders.

The proportion of MSM who reported never having tested for HIV was higher in the North and Northeast when compared to other regions: $26 \%$ in Manaus and Belém and $12 \%$ in Santos, Curitiba and Brasília. The main reason for never testing for HIV were, in order, "I am afraid of getting a positive result" (851; 32.4\%), "I am ashamed" (559; 21.3\%), "I am not at risk of getting infected" (459; 17.5\%), "I am too lazy" (293; 11.2\%), "I don't think it is practical to go to a health care center" (234; 8.9\%) and others (227; 8.7\%). This pattern was observed in all Brazilian regions except for the South where the response "I am not at risk of getting infected" was more frequent than "I am ashamed" (22\% vs. $19 \%$ ). In the North, more MSM reported "I am afraid of getting a positive result" (38\%) in comparison to the other regions (Fig. 1).

Overall, the number of responders who reported sex with more than five men was lower in Northern and Northeastern cities compared to the other regions, around $35 \%$. In contrast, this proportion was higher in Southeastern cities, São Paulo (46.2\%), Rio de Janeiro (45.4\%), Brasília (44.8\%) and in the Southern cities, ranging from $43.5 \%$ in Curitiba to $45.5 \%$ in Porto Alegre. Condomless receptive anal sex was reported by 6865 participants $(41.4 \%)$ with little heterogeneity by city. Most participants met criteria for "high risk" according to the HIRI-MSM (64.3\%), indicating that PrEP should be recommended. Conversely, only $28.0 \%$ of participants reported high HIV perceived risk, and this proportion was lower in Belém (23.5\%) and Recife (24.9\%).

Table 3 shows that irrespective of the definition of high-risk behavior, overall, high-risk behavior was associated with a 3-fold increase in the odds of high HIV perceived risk. That said, less than a half of those with high-risk behavior (as measured by a score $>10$ in the HIRI-MSM, condomless receptive anal sex, or $>5$ partners in the prior 6 months) perceived themselves at high risk. In contrast, among those reporting low-risk behavior, around one-fifth perceived themselves at high-risk (13.9\% as measured by the HIRI-MSM, $19.7 \%$ who report condomless anal sex and $18.8 \%$ who had $\leq 5$ partners). Finally, we found evidence for a significant association between sexual behavior with HIV perceived risk in the 11 cities according to the HIRI-MSM and report of condomless anal sex (Tables 4 and 5).

Overall, the association of socio-demographic and behavioral characteristics with high-risk behavior as 


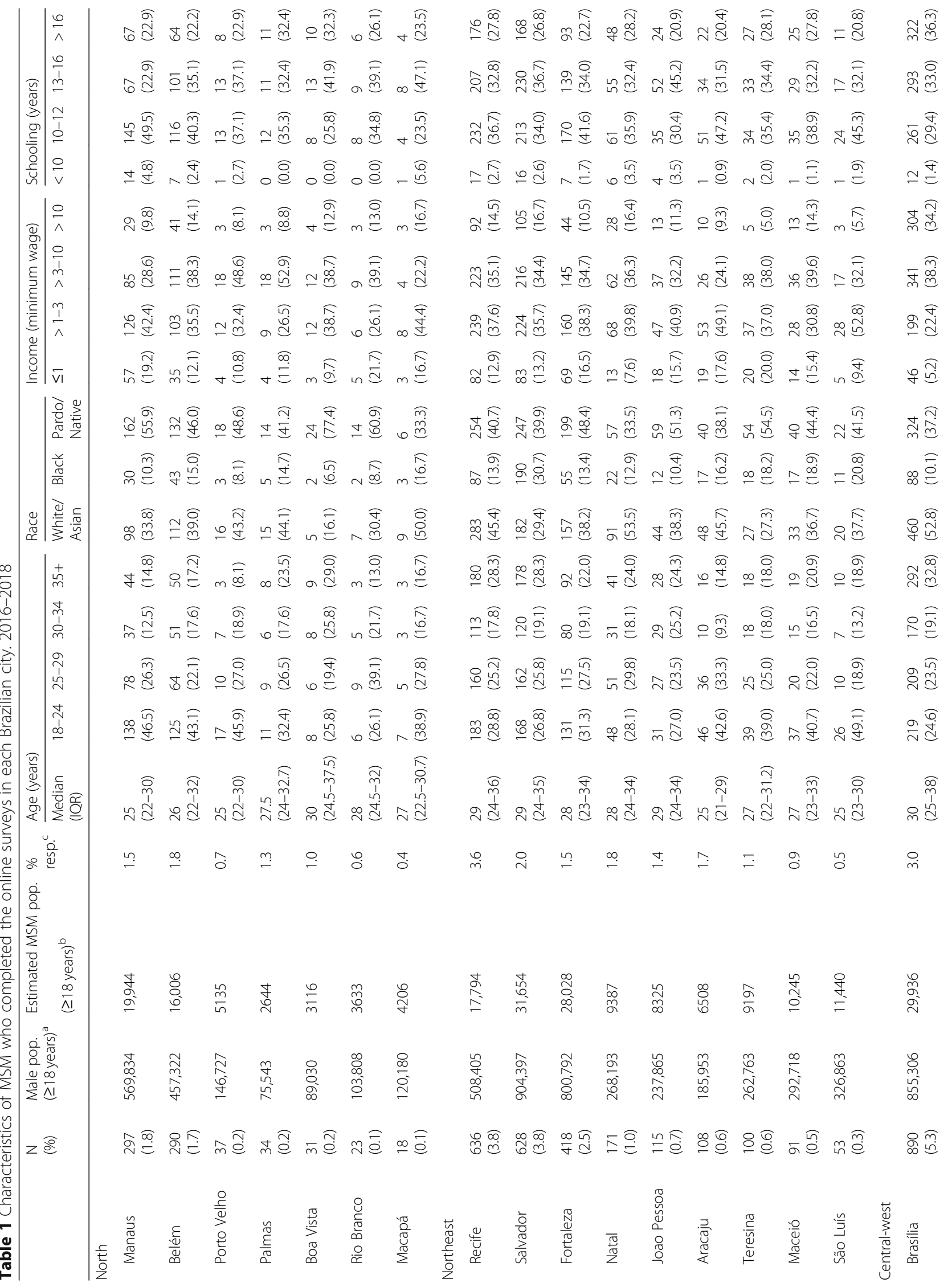




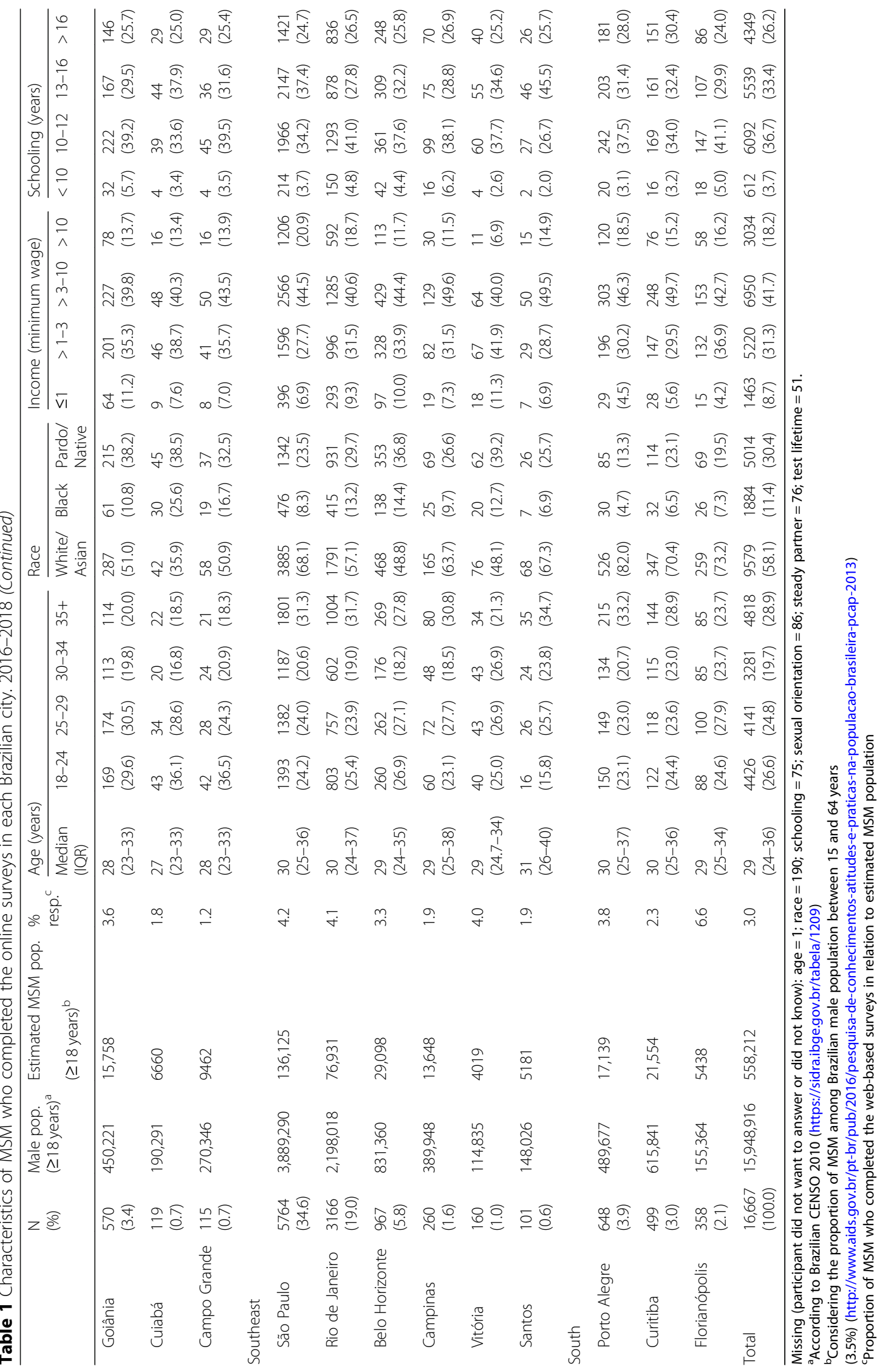




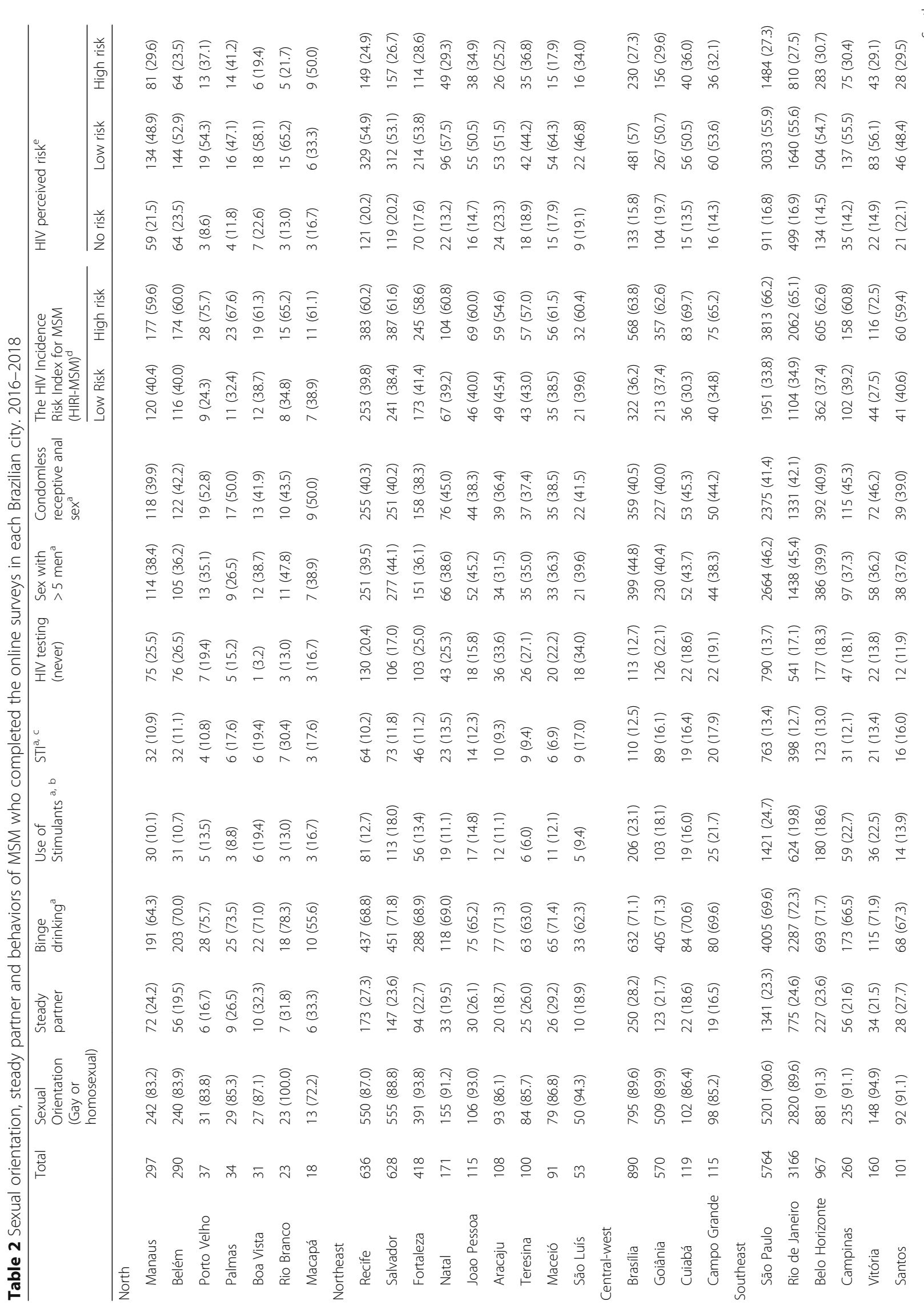




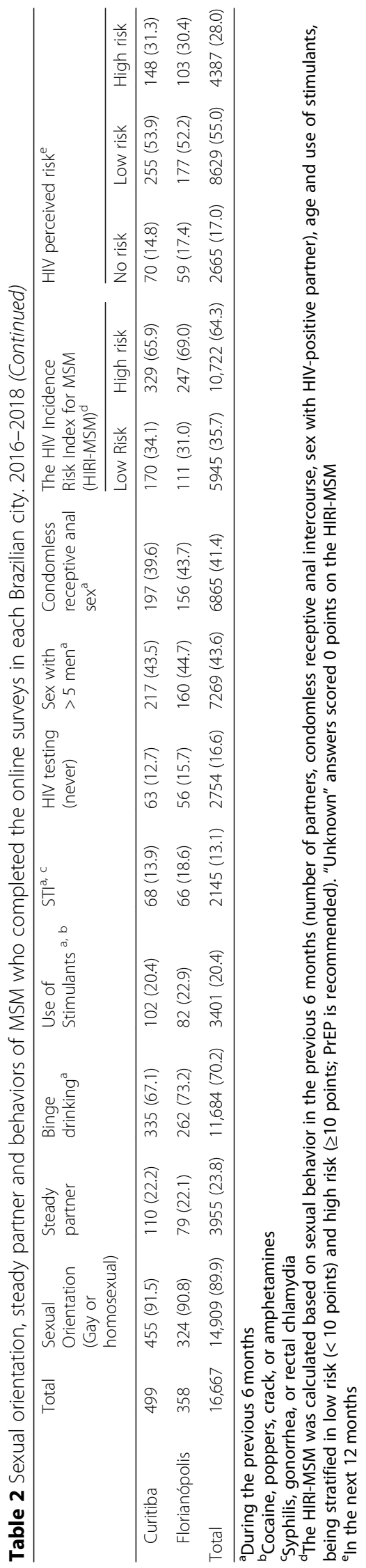




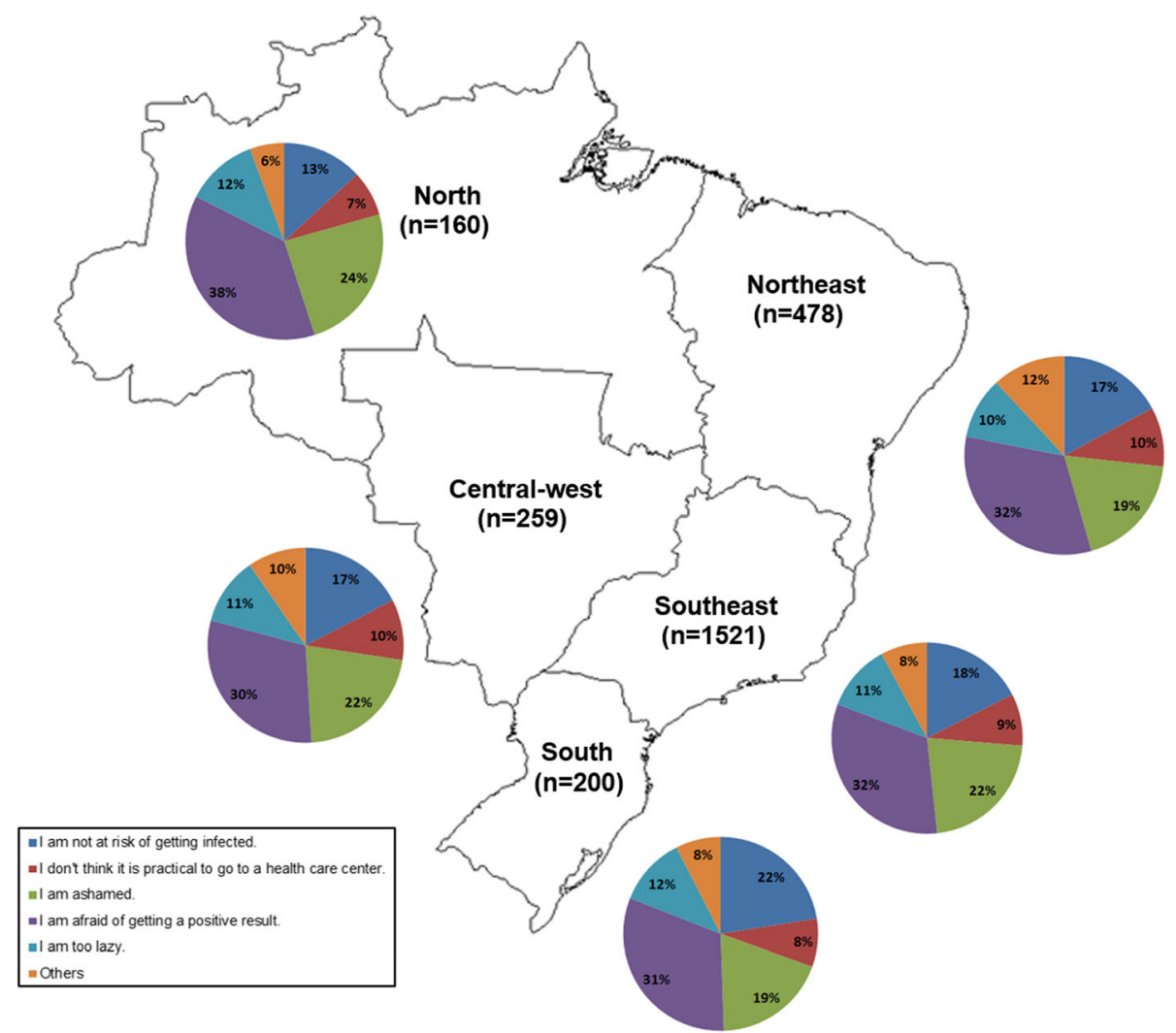

Fig. 1 Distribution of responses to the question "Why have you never tested for HIV?" by Brazilian Geopolitical Region $(n=2618)$

Table 3 Association between HIV risk behavior and HIV perceived risk among MSM who completed the online surveys in Brazil

\begin{tabular}{|c|c|c|c|}
\hline & \multicolumn{2}{|c|}{ HIV Perceived risk ${ }^{a}$} & \multirow{2}{*}{$\begin{array}{l}\text { High HIV } \\
\text { perceived risk } \\
\text { OR }(95 \% \mathrm{Cl})\end{array}$} \\
\hline & Low & High & \\
\hline \multicolumn{4}{|c|}{ The HIV incidence risk index for MSM ${ }^{b}$} \\
\hline Low & $4860(86.1)$ & $784(13.9)$ & Ref. \\
\hline High & $6434(64.1)$ & $3603(35.9)$ & $3.47(3.19-3.78)$ \\
\hline \multicolumn{4}{|c|}{ Condomless receptive anal sex ${ }^{c}$} \\
\hline No & $7400(80.3)$ & $1811(19.7)$ & Ref. \\
\hline Yes & $3847(60.1)$ & $2552(39.9)$ & $2.71(2.52-2.91)$ \\
\hline \multicolumn{4}{|c|}{ Number of male partners $^{c}$} \\
\hline$\leq 5$ & $7213(81.2)$ & $1671(18.8)$ & Ref. \\
\hline$>5$ & $4081(60.0)$ & $2716(40.0)$ & $2.87(2.67-3.09)$ \\
\hline
\end{tabular}

an the next 12 months

${ }^{\mathrm{b}}$ The HIRI-MSM was calculated based on sexual behavior in the previous 6 months (number of partners, condomless receptive anal intercourse, sex with HIV-positive partner), age and use of stimulants, being stratified in low risk (< 10 points) and high risk ( $\geq 10$ points; PrEP is recommended)."Unknown" answers scored 0 points on the HIRI-MSM

'During the previous 6 months measured by the HIRI-MSM was consistent across the cities (Table 6). Younger age, being gay or homosexual, having a steady partner, binge drinking, STI diagnosis and ever testing for HIV increased the odds of high-risk behavior. As participants from São Paulo and Rio de Janeiro make up the majority of the study population, the results of Brazil as a whole greatly reflect those for these two cities. One notable exception was the association of having a steady partner increasing the odds of high-risk behavior which is most strongly observed in Goiania. Similarly, the association of binge drinking with high-risk behavior is more pronounced in the North, Central-west, and South, and not apparent in the Northeast.

Overall, PrEP awareness increased overtime in Brazil from 58\% in 2016 to $70 \%$ in 2018 (Fig. 2). Among the 10 cities evaluated in all surveys, São Paulo had the highest proportion of awareness in 2016 (63\%) and 2018 (74\%), and Recife the lowest in 2018 (58\%). Manaus had the greatest increase in PrEP awareness (from 40\% in 2016 to $62 \%$ in 2018). Willingness to use PrEP also increased overtime in Brazil, from 52\% in 2016 to $63 \%$ in 2018 . The highest increase in willingness to use PrEP was in Manaus, from the lowest value in 2016 (50\%) to the highest in 2018 (70\%). A substantial increase in 
Table 4 HIV risk behavior vs. HIV perceived risk among MSM from 11 cities in Brazil

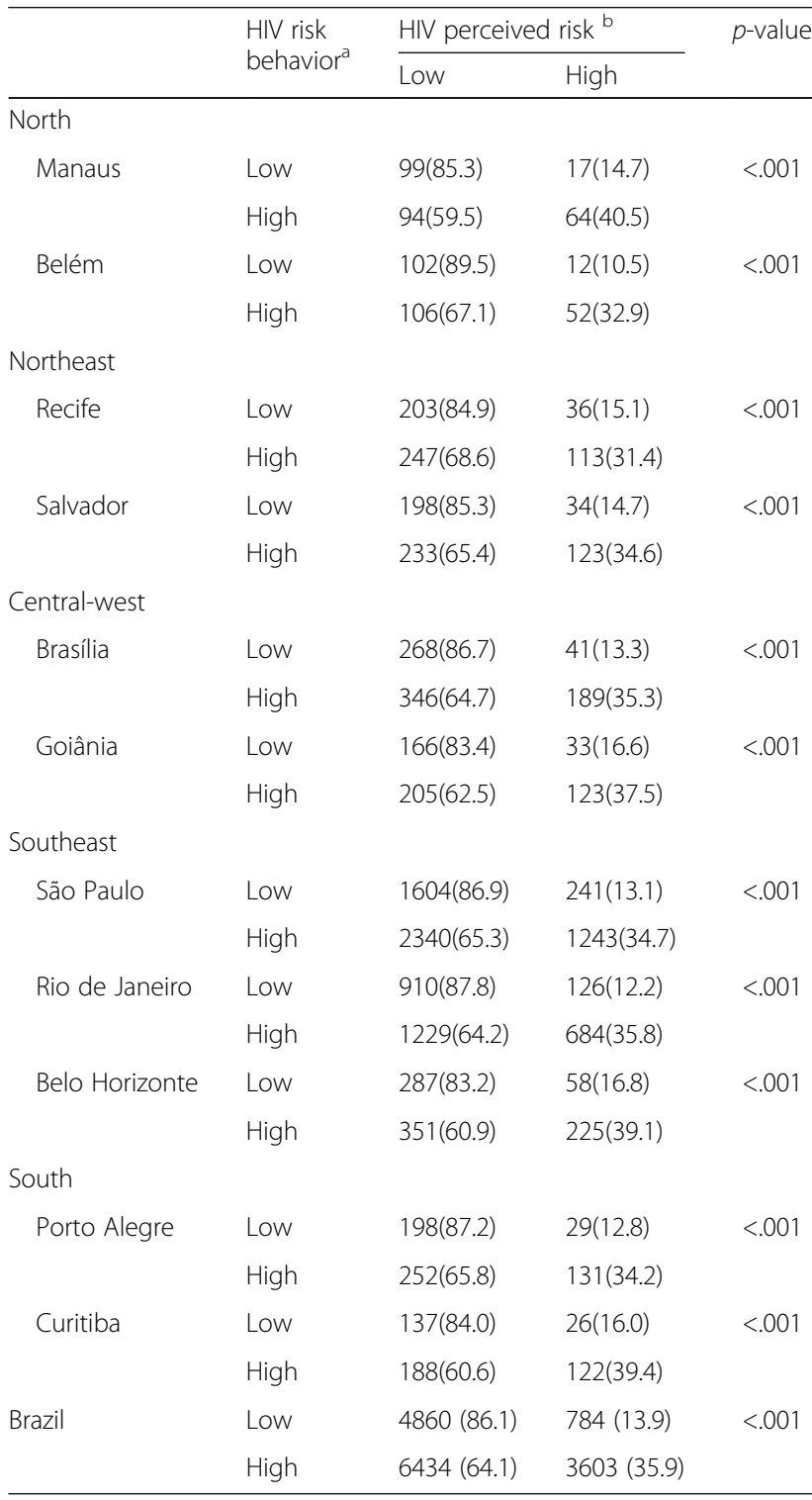

${ }^{a}$ measured by the HIRI-MSM, which was calculated based on sexual behavior in the previous 6 months (number of partners, condomless receptive anal intercourse, sex with HIV-positive partner), age and use of stimulants, being stratified in low risk ( $<10$ points) and high risk ( $\geq 10$ points; PrEP is recommended)

${ }^{\mathrm{b}}$ HIV perceived risk (in the next 12 months) was dichotomized in low (no/low) and high risk

willingness to use PrEP was also observed for Porto Alegre (48\% in 2016 to $67 \%$ in 2018) and Rio de Janeiro (55\% in 2016 to $69 \%$ in 2019). Across the years, willingness to use PrEP was almost stable in Goiânia (58\% in 2016 and 2018), Florianópolis (58\% in 2016 and 61\% in 2018) and Brasília (56\% in 2016 to 62\% in 2018) (Fig. 2).

\section{Discussion}

In the present, we described the socio-demographic characteristics as well as sexual behavior and HIV
Table 5 Condomless receptive anal sex vs. HIV perceived risk among MSM from 11 cities in Brazil

\begin{tabular}{|c|c|c|c|c|}
\hline & \multirow{2}{*}{$\begin{array}{l}\text { Condomless } \\
\text { receptive anal } \\
\text { sex }^{a}\end{array}$} & \multicolumn{2}{|c|}{ HIV perceived risk ${ }^{b}$} & \multirow[t]{2}{*}{$p$-value } \\
\hline & & Low & High & \\
\hline \multicolumn{5}{|l|}{ North } \\
\hline \multirow[t]{2}{*}{ Manaus } & No & 133(79.6) & $34(20.4)$ & $<.001$ \\
\hline & Yes & $60(56.6)$ & $46(43.4)$ & \\
\hline \multirow[t]{2}{*}{ Belém } & No & 137(85.6) & $23(14.4)$ & $<.001$ \\
\hline & Yes & $71(64.0)$ & $40(36.0)$ & \\
\hline \multicolumn{5}{|l|}{ Northeast } \\
\hline \multirow[t]{2}{*}{ Recife } & No & 295(82.4) & 63(17.6) & $<.001$ \\
\hline & Yes & 153(64.3) & $85(35.7)$ & \\
\hline \multirow[t]{2}{*}{ Salvador } & No & 292(81.3) & $67(18.7)$ & $<.001$ \\
\hline & Yes & 138(60.8) & 89(39.2) & \\
\hline \multicolumn{5}{|l|}{ Central-west } \\
\hline \multirow[t]{2}{*}{ Brasília } & No & $400(79.4)$ & 104(20.6) & $<.001$ \\
\hline & Yes & $212(62.9)$ & $125(37.1)$ & \\
\hline \multirow[t]{2}{*}{ Goiânia } & No & 247(77.9) & $70(22.1)$ & $<.001$ \\
\hline & Yes & 123(59.1) & $85(40.9)$ & \\
\hline \multicolumn{5}{|l|}{ Southeast } \\
\hline \multirow[t]{2}{*}{ São Paulo } & No & 2592(81.5) & $590(18.5)$ & $<.001$ \\
\hline & Yes & 1334(60.0) & $889(40.0)$ & \\
\hline \multirow[t]{2}{*}{ Rio de Janeiro } & No & 1397(81.6) & $314(18.4)$ & $<.001$ \\
\hline & Yes & $741(60.0)$ & $494(40.0)$ & \\
\hline \multirow[t]{2}{*}{ Belo Horizonte } & No & $414(76.4)$ & 128(23.6) & $<.001$ \\
\hline & Yes & 218(58.6) & 154(41.4) & \\
\hline \multicolumn{5}{|l|}{ South } \\
\hline \multirow[t]{2}{*}{ Porto Alegre } & No & $290(81.5)$ & $66(18.5)$ & $<.001$ \\
\hline & Yes & $160(63.2)$ & 93(36.8) & \\
\hline \multirow[t]{2}{*}{ Curitiba } & No & $221(76.5)$ & $68(23.5)$ & $<.001$ \\
\hline & Yes & 103(56.3) & $80(43.7)$ & \\
\hline \multirow[t]{2}{*}{ Brazil } & No & 7400 (80.3) & 1811 (19.7) & $<.001$ \\
\hline & Yes & $3847(60.1)$ & 2552 (39.9) & \\
\hline
\end{tabular}

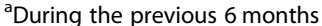

${ }^{\mathrm{b}}$ HIV perceived risk (in the next 12 months) was dichotomized in low (no/low) and high risk

perceived risk by city across all regions of Brazil. We noted significant heterogeneity with respect to some factors (i.e. socio-demographic characteristics, stimulant use and never testing for HIV) and a homogeneous profile for others (binge drinking and sexual behavior). Moreover, our results highlight which factors were most associated with high-risk behavior by city and in the country.

One strength of this study was the inclusion of a large number of MSM living in Brazilian state capitals, in the Federal District and in two large cities from São Paulo state. Considering the estimated population of MSM in 


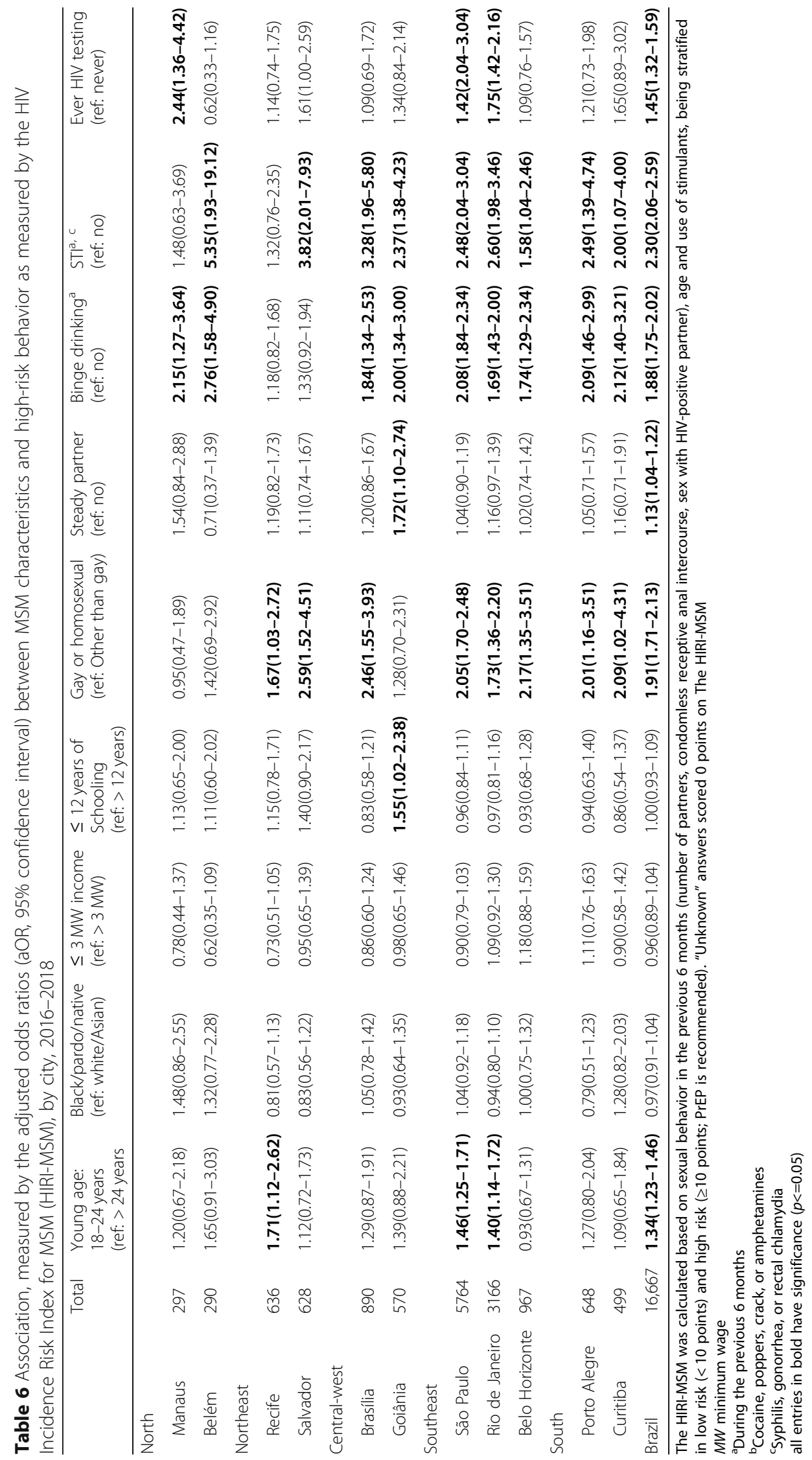



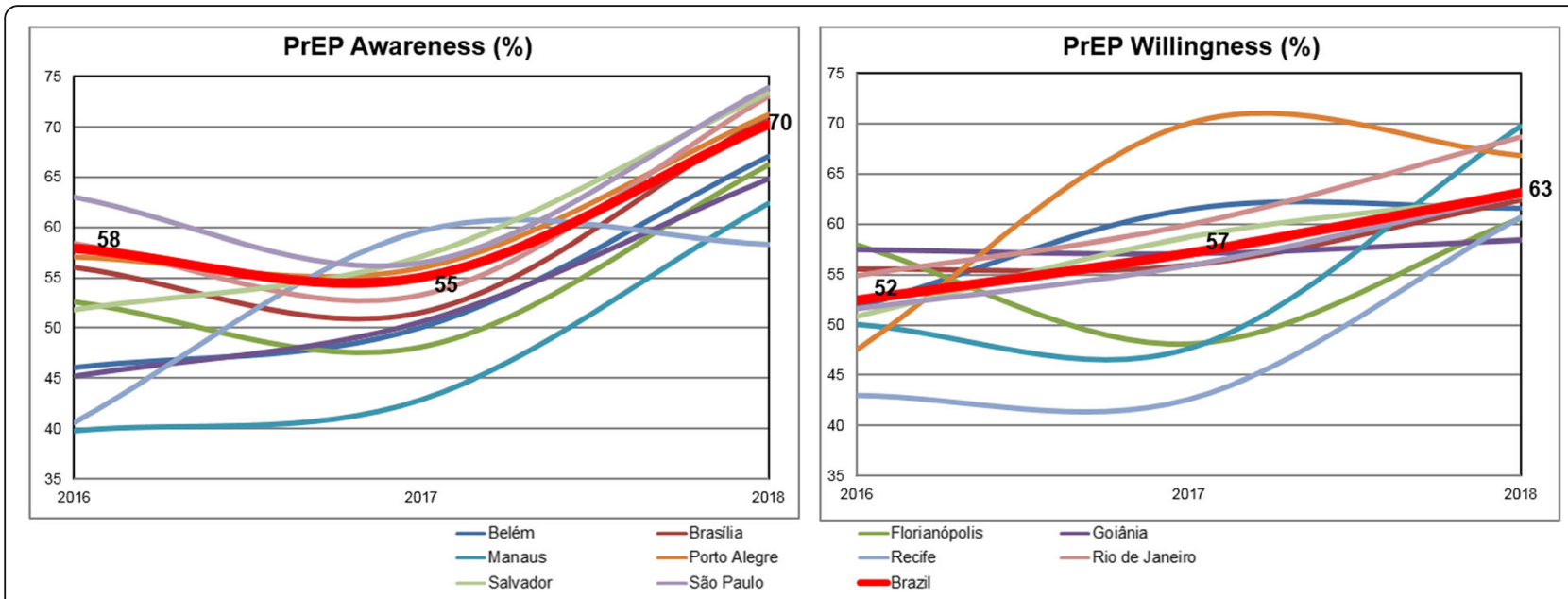

Fig. 2 Awareness and willingness to use PrEP among MSM from 10 Brazilian State Capitals from 2016 to 2018

each city, the highest proportions of MSM completing the questionnaire were from the South, Southeast and Central-west regions. Compared to the North and Northeast, these regions are more developed likely providing greater access to and use of mobile phones and cell phone data services and/or public Wi-Fi services on a daily basis [17], thus facilitating participation. Differential participation among cities could also result from differential use of apps for sexual encounters by the MSM community of each city.

We observed similarities among MSM from 1) the South, Southeast and Brasilia versus those from 2) the North and Northeast. Different from group 1), for group 2) a greater proportion of MSM were young, non-white, of lower income and lower schooling, which are characteristics of the population most vulnerable to HIV infection in Brazil [7]. These group differences could be a reflection of the socio-demographic characteristics of the population from these regions according to national data [18]. Despite large inequalities, Brazil has a large number of internet users in all social strata: $58 \%$ of individuals receiving one minimum wage per month ( US\$260.00) have access to internet [17]. According to estimates, $84 \%$ of Brazilians have a mobile phone [19] and 96\% have access to internet/apps via mobile phones [20]. This supports the use of apps and social media to broadcast information on sexual education and HIV/STI treatment and prevention.

MSM reporting high-risk behavior measured by the HIRI-MSM, condomless receptive anal sex and increased number of partners were more likely to perceive themselves at higher risk, which is consistent with a web-based study conducted among 800 MSM from the United States [21]. However, we also found that a high proportion of MSM reporting high-risk behavior do not perceive themselves at high-risk for HIV $(\sim 60 \%)$. This difference was also observed in other studies conducted in different settings [22-30] and could reflect a dissonance between sexual behavior and HIV transmission knowledge. Previous studies have shown a relationship between sexual behavior or low HIV perceived risk and mistaken beliefs about HIV transmission and epidemiology [31, 32]. A Brazilian study conducted in 2008/9 evaluated HIV knowledge among MSM from 10 Brazilian cities and found that $41 \%$ of the sample had lower than average knowledge with participants still reporting beliefs in incorrect modes of HIV transmission such as through the use of a public restroom [33]. In another study conducted in 2016 [34], knowledge was found to vary by region with an overall prevalence of high level of knowledge of $24 \%$ that ranged from $5 \%$ in Fortaleza to $34 \%$ in São Paulo. Importantly, low HIV perceived risk may be a barrier to PrEP uptake [35]. Health care providers should take every opportunity to provide and reinforce information on HIV transmission and prevention. This would empower MSM to make decisions and manage their risk safely.

In our analysis of factors associated with high-risk behavior, we found that MSM who self-declared as gay or homosexual compared to other sexual orientations (bisexual, heterosexual or other) had greater odds of highrisk behavior. A longitudinal analysis partner-level data on self-declared gay and bisexual men's behaviors has shown that behaviors depend on the type of relationship (casual versus serious) and on the type of condomless anal sex (receptive versus insertive) [36]. Of relevance to our findings, bisexual men reported more insertive condomless anal sex with casual male partners compared to self-identified gay men [36]. Although the proportion of non-gay MSM in the sample was low and includes selfdeclared bisexual MSM, our results likely reflect the higher frequency of receptive condomless anal sex 
among self-declared gay or homosexual as compared to men who report other sexual orientations. This finding is worrisome specially when coupled with those from a 2016 cross-sectional analysis of over 37 thousand young army conscripts in Brazil, 4.4\% of which reported being MSM, who reported significant less condom use with casual partners compared to stable partners [37].

MSM who reported binge drinking were also found at higher odds of high-risk behavior. Binge drinking is known to increase high-risk behaviors among MSM [38-40]. In our study, binge drinking was highly prevalent across the cities $(\sim 70 \%)$, while more MSM from the Central-west, South and Southeast regions $(\sim 20 \%)$ reported use of stimulants (compared to $\sim 10 \%$ in the North and Northeast). Alcohol is widely used, accepted and easy to access in Brazil [41]. Stimulants, in contrast, are expensive and illegal; access may be easier in larger urban areas, what may explain these disparities [42].

Regarding our socio-demographic factors, though there was no association of race, income or education with high-risk behavior (be it overall or by city except for 1 city), we found that younger age was associated with an increased odds of high-risk behavior. This finding is of great concern and might help explain the recent rise in HIV incidence among MSM aged 16-24 years in Brazil [7]. A recent Thai study reported similar results among MSM attending a gay sauna, where young MSM were at higher-risk compared to older MSM due to their higher risk behaviors and false perception of low HIV risk [43]. One explanation of this finding might be that younger individuals may be more fearless of HIV and/or optimistic of HIV treatment and prevention strategies [44-46]. In a web-based survey conducted among MSM from the US, younger MSM had higher knowledge of HIV prevention compared to the older, but no differences regarding HIV perceived risk [47]. However, in Brazil, sexual education at schools or within the families are still a taboo and may impact knowledge of HIV transmission risk and prevention strategies [33]. Youngfriendly interventions to increase awareness of HIV risk behaviors and prevention technologies are urgent to stop new HIV infections among young MSM in Brazil.

Having a steady partner was also associated with increased odds of high-risk behavior. Risk perception decreases when feelings of trust grow in relationships [48]. Accordingly, MSM may feel more comfortable to have condomless sex with a steady partner and may perceive no or low risk with this behavior [49]. An open conversation between the couple or with the support of a health professional would be beneficial for risk management. PrEP could be an option in case of open or nonmonogamic relationships as it does not depend on an agreement during sex (as condoms do). Moreover, when thinking specifically about serodiscordant couples, recent results from Opposites Attract suggest that PrEP might be useful in the initial months of a relationship or during the first months of ART initiation, after which ARTinduced viral suppression is likely sufficient [50]. Here, the need to disseminate the knowledge that $\mathrm{U}=\mathrm{U}$ (undetectable $=$ untransmissible) should be emphasized [51]. As suggested in a recent review of HIV epidemiology in Latin America [4], $\mathrm{U}=\mathrm{U}$ knowledge "empowers people living with HIV, improves adherence and decreases selfstigma" and it may also improve intimate relationships by decreasing fear of transmission.

Finally, having an STI and ever testing for HIV were both associated with increased odds of high-risk behavior. In fact, the association between having an STI with high-risk behavior was the largest in magnitude when compared to all other factors. In Brazil, STI diagnosis still relies extensively on syndromic management [52] suggesting that these infections were symptomatic. The observed association of high-risk behavior with STI diagnosis evidences the concomitant increased risk of HIV infection to which these men are exposed to. The interaction with health professionals at the time of STI diagnosis needs to be used for the provision of information on HIV risk thus increasing knowledge and awareness of one's risk. This highlights the importance of health care providers as source of information and sexual education. Though it is comforting to know that MSM who engage in high-risk behavior were also more likely to test for HIV, the magnitude of the effect of STI diagnosis was much higher than that of ever testing. Of note is the present study's conservative assessment of HIV testing as at least once in lifetime.

Overall, almost $17 \%$ of the surveyed MSM reported never having tested for HIV (median age 29 years), which can be considered quite high as the CDC recommends that everyone aged 13-64 years should be tested at least once and that sexually active gay and bisexual men benefit from more frequent testing (e.g. every 3 to 6 months) [53]. This proportion was even higher in the North and the Northeast. This may be related to limited access to health services in these regions, though only $7-10 \%$ of those who never tested reported that it was not practical to go to a health care center. The main reasons for not testing ("I am afraid of getting a positive result" and "I am ashamed") reflects the persistent HIV stigma in Brazil with fear of HIV stigma hindering HIV testing. In a study conducted in New York City, MSM and transgender women afraid of HIV stigma were less likely to get tested $[54,55]$. In addition, some MSM already face stigma for being gay and a possible HIV diagnosis would represent a new stigma to bear. HIV testing is a key technology within the HIV prevention package, it is the necessary step to linkage to care and treatment for those with HIV infection and to 
prevention services for those with a negative result. Information on the benefits of early HIV diagnosis and antiretroviral therapy initiation to decrease comorbidities related and not related to AIDS [56] and to decrease HIV transmission [50, 57] are essential to decrease stigma, increase HIV testing and, as consequence, decrease new cases of HIV. HIV self-testing, which is available commercially in Brazil, can play in an important role in increasing testing, although awareness of this technology is still low in the country $[11,12,58]$. A previous analysis verified that MSM willing to use PrEP were also willing to use HIV self-testing, indicating that both technologies could be offered in the same platform, which could be web-based [58].

In this regard, it is encouraging that awareness and willingness to use PrEP increased overtime in Brazil though it varied according to the evaluated cities. In concordance, other studies have shown an increase in awareness and willingness to use PrEP in Brazil from 2014 to 2018 [10-12, 16]. This is likely the result of the expansion of PrEP demonstration projects to other cities (e.g. inclusion of Manaus and Porto Alegre to PrEP Brasil study) [59], the initiation of ImPrEP demonstration study in 12 Brazilian cities (http://imprep.org/) and the campaigns to increase PrEP knowledge among key populations in websites (e.g. http://prepbrasil.com.br), social media (e.g. http://facebook.com/prepbrasil) and apps for sexual encounters. That being said, a qualitative study conducted in 2016 in Salvador, Bahia, in the Northeast of Brazil, showed limited knowledge and willingness to use PrEP in their population and highlighted the importance of raising knowledge on the benefits and possible adverse events following PrEP uptake [60]. Acknowledging the heterogeneity in PrEP awareness is important as PrEP is being offered at no cost to highrisk populations in the Brazilian Public Health System. Increased efforts and resources in particular cities or regions are paramount to increase awareness and create demand for PrEP.

This study has limitations. First, web-based studies are not probabilistic sampling strategies, precluding the generalization of the findings to all Brazilian MSM. Considering this is an online convenience sample, geographic comparisons should be analyzed with caution. Moreover, our findings are based on MSM who have access to cellphones and who use GSN apps or social media so it is not generalizable to all MSM in Brazil. Recent data from the Brazilian Institute of Geography and Statistics suggests that $76 \%$ of the Brazilian population has access to internet connection [17]. Given the crosssectional nature of the data, causality and the direction of association may not be inferred. All collected data were self-reported by participants and may be subject to bias. However, individuals tend to be more open and honest through web-based surveys, thereby reducing the possibility of social desirability bias [61]. Our data are subject to recall bias due to 6-month or 12-month recall periods. There is also a concern about participants taking the survey multiple times. To mitigate this bias, the first question of the survey was, "Are you answering this survey for the first time?". On the definition of our highrisk behavior outcomes, we used three different definitions that have been consistently used in other studies as well as in guidelines to define populations at substantial risk of HIV infection [14-16, 62-64]. The use of the HIRI-MSM as the outcome in the regression model precluded the evaluation of stimulants use as a covariate as it is already included in the scale. Instead, we focused on the effect of alcohol use as measured by binge drinking. Finally, we did not collect data on "sex with HIVinfected partners on antiretroviral treatment with undetectable viral load" and thus could not explore how this might have impacted the association of HIV perceived risk with sexual behavior.

\section{Conclusions}

Overall, MSM socio-demographic characteristics were heterogeneous among Brazilian cities, but similarities were noted among the cities from the same administrative region with a marked exception of the Federal District not following the patterns for the Central-West region. Some behaviors were more homogeneous across the country, including high-risk sexual behavior, though never testing for HIV was notably higher in the least developed cities. Combination HIV prevention is most needed among young men who self-identify as gay/ homosexual, report binge drinking or prior STI.

\section{Supplementary information}

Supplementary information accompanies this paper at https://doi.org/10. 1186/s12879-019-4704-x.

\section{Additional file 1. Brazilian MSM Survey Instrument. The survey instrument is composed of five sections ( 25 questions) addressing: sociodemographic information, substance use, sexual behavior and history of sexually transmitted infections, HIV perceived risk and use of HIV testing as well as awareness and willingness to use PrEP.}

\section{Abbreviations}

AIDS: acquired immunodeficiency syndrome; CDC: Centers for Disease Control and Prevention; Cl: confidence interval; FTC/TDF: emtricitabine and tenofovir disoproxil fumarate; GDP: gross domestic product; GSN: geosocial networking; HDI: human development index; HIRI-MSM: HIV Incidence Risk Index for MSM; HIV: human immunodeficiency virus; IQR: interquartile range; LGBTQI: lesbian, gay, bisexual, transgender, queer and intersex; MSM: gays, bisexuals and other men who have sex with men; MW: minimum wage; OR: odds ratio; PrEP: pre-exposure prophylaxis; STI: sexually transmitted infections; SUS: Brazilian Public Health System

\section{Acknowledgments}

We would like to thanks Gabriel Madeira for programming the questionnaires and Daniel R B Bezerra for social media consulting. 


\section{Authors' contributions}

TST and PML did the literature search. TST, LMSM, VGV, BG and PML conceived and implemented the study. TST analyzed the data and generated the tables and figures. TST and PML interpreted the data and draft the manuscript. LMSM, VGV and BG substantively revised the manuscript for important intellectual content. All authors read and approved the final manuscript.

\section{Funding}

Gilead Sciences covered the costs related to advertisement of the survey on 2016 and 2017. The 2018 survey was made possible thanks to Unitaid's funding and support. Unitaid accelerates access to innovative health products and lays the foundations for their scale-up by countries and partners. Gilead and Unitaid played no role in the study design, collection, analysis, or interpretation of data, the writing of the manuscript, or the decision to submit this manuscript for publication.

\section{Availability of data and materials}

The datasets analyzed during the current study are available from the corresponding author on reasonable request.

\section{Ethics approval and consent to participate}

INI Evandro Chagas-FIOCRUZ institutional review board approved this study (\#CAAE 51595815.7.0000.5262 and 82021918.0.0000.5262) in accordance with all applicable regulations and all study participants digitally signed an informed consent form. No form of identification of participants was collected.

\section{Consent for publication}

Not applicable.

\section{Competing interests}

The authors declare that they have no competing interests.

Received: 14 August 2019 Accepted: 12 December 2019

Published online: 19 December 2019

\section{References}

1. Rio HDI per neighborhoods [Internet]. Available from: https://www.wikirio. com.br/IDH_dos_bairros_da_cidade_do_Rio_de_Janeiro.

2. World Population [Internet]. Available from: https://www.worldometers.info/ world-population/population-by-country.

3. Boni RD, Veloso V, Grinsztejn B. Epidemiology of HIV in Latin America and the Caribbean. Curr Opin HIV AIDS. 2014:9(2):192-8.

4. Luz PM, Veloso VG, Grinsztejn B. The HIV epidemic in Latin America: accomplishments and challenges on treatment and prevention. Curr Opin HIV AIDS. 2019;14:366-73.

5. Kerr L, Kendall C, Guimarães MDC, Salani Mota R, Veras MA, Dourado I, et al. HIV prevalence among men who have sex with men in Brazil: results of the 2nd national survey using respondent-driven sampling. Medicine (Baltimore). 2018;97(1 Suppl):S9-S15 Available from: https://www.ncbi.nlm. nih.gov/pmc/articles/PMC5991534/ [cited 2019 Jul 9].

6. Kerr L, Mota R, Kendall C, de Pinho A, Mello M, Guimarães M, et al. HIV among MSM in a large middle-income country. Aids. 2013;27(3):427-35.

7. Brasil, Ministério da Saúde. Boletim epidemiológico HIV/Aids 2018 [Internet]. 2018. Available from: http://www.aids.gov.br/pt-br/pub/2018/boletimepidemiologico-hivaids-2018.

8. Brasil, Ministério da Saúde. Pesquisa de Conhecimentos, Atitudes e Práticas na População Brasileira - PCAP 2013 [Internet]. 2016. Available from: http://www.aids.gov.br/pt-br/pub/2016/pesquisa-de-conhecimentosatitudes-e-praticas-na-populacao-brasileira-pcap-2013.

9. World Health Organization (WHO). WHO | Brazil begins PrEP roll-out on World AIDS Day [Internet]. WHO. [cited 2019 Jul 9]. Available from: http://www.who.int/hiv/mediacentre/news/brazil-prep/en/.

10. Torres TS, De Boni RB, de Vasconcellos MT, Luz PM, Hoagland B, Moreira RI, et al. Awareness of prevention strategies and willingness to use preexposure prophylaxis in Brazilian men who have sex with men using apps for sexual encounters: online cross-sectional Study. JMIR Public Health Surveill. 2018;4(1):e11.

11. Torres TS, Luz PM, De Boni RB, de Vasconcellos MTL, Hoagland B, Garner A et al. Factors associated with PrEP awareness according to age and willingness to use HIV prevention technologies: the 2017 online survey among MSM in Brazil. AIDS Care. 2019;23:1-10.

12. Torres TS, Konda KA, Vega-Ramirez EH, Elorreaga OA, Diaz-Sosa D, Hoagland $B$, et al. Factors associated with willingness to use pre-exposure prophylaxis in Brazil, Mexico, and Peru: web-based survey among men who have sex with men. JMIR Public Health Surveill. 2019 Jun 17:5(2):e13771.

13. National Institute on Alcohol Abuse and Alcoholism (NIAAA), Abuse and Alcoholism (NIAAA). NIAAA approves definition of binge drinking [Internet]. 2004. Available from: https://pubs.niaaa.nih.gov/publications/Newsletter/ winter2004/Newsletter_Number3.pdf.

14. Smith DK, Pals SL, Herbst JH, Shinde S, Carey JW. Development of a clinical screening index predictive of incident HIV infection among men who have sex with men in the united states. J Acquir Immune Defic Syndr. 2012;60(4): $421-7$.

15. US Centers for Disease Control (CDC). Preexposure prophylaxis for the prevention of hiv infection in the united states -2017 update clinical providers' supplement [Internet]. 2017. Available from: https://www.cdc.gov/ hiv/pdf/risk/prep/cdc-hiv-prep-provider-supplement-2017.pdf.

16. For the PrEP Brasil Study Team, Hoagland B, De Boni RB, Moreira RI, Madruga JV, Kallas EG, et al. Awareness and willingness to use pre-exposure prophylaxis (PrEP) among men who have sex with men and transgender women in Brazil. AIDS Behav. 2017;21(5):1278-87.

17. Comitê Gestor da Internet no Brasil (CGIBR). TIC Domicílios. C2A - USUÁRIOS DE INTERNET - INDICADOR AMPLIADO [Internet]. Cetic.br - Centro Regional para o Desenvolvimento da Sociedade da Informação. 2017. Available from: https://www.cetic.br/tics/domicilios/2017/individuos/C2A/ [cited 2019 Jul 9].

18. Instituto Brasileiro de Geografia e Estatística (IBGE). Censo Demográfico. Tabela 3175: População residente, por cor ou raça, segundo a situação do domicílio, o sexo e a idade [Internet]. 2010. Available from: https://sidra.ibge. gov.br/Tabela/3175 [cited 2019 Jul 9].

19. Comitê Gestor da Internet no Brasil (CGIBR). TIC Domicílios. J2 - INDIVÍDUOS QUE POSSUEM TELEFONE CELULAR [Internet]. Cetic.br - Centro Regional para o Desenvolvimento da Sociedade da Informação. 2017. Available from: https://www.cetic.br/tics/domicilios/2017/individuos/J2/ [cited 2019 Jul 9].

20. Comitê Gestor da Internet no Brasil (CGIBR). TIC Domicílios. C16 - USUÁRIOS DE INTERNET, POR DISPOSITIVO UTILIZADO [Internet]. Cetic.br - Centro Regional para o Desenvolvimento da Sociedade da Informação. 2017. Available from: https://www.cetic.br/tics/domicilios/2017/individuos/C16/ [cited 2019 Jul 9]

21. Kahle EM, Sharma A, Sullivan SP, Stephenson R. HIV prioritization and risk perception among an online sample of men who have sex with men in the United States. Am J Mens Health. 2018;12(4):676-87.

22. Klein H, Tilley DL. Perceptions of HIV risk among internet-using, HIV-negative Barebacking men. Am J Mens Health. 2012;6(4):280-93.

23. Mustanski B, Johnson AK, Garofalo R, Ryan D, Birkett M. Perceived likelihood of using HIV pre-exposure prophylaxis medications among young men who have sex with men. AIDS Behav. 2013:17(6):2173-9.

24. Liu C, Ding Y, Ning Z, Gao M, Liu X, Wong FY, et al. Factors influencing uptake of pre-exposure prophylaxis: some qualitative insights from an intervention study of men who have sex with men in China. Sex Health. 2017:15(1):39-45.

25. Blumenthal J, Jain S, Mulvihill E, Sun S, Hanashiro M, Ellorin E, et al. Perceived versus calculated HIV risk: implications for pre-exposure prophylaxis uptake in a randomized trial of men who have sex with men. J Acquir Immune Defic Syndr. 2019;80(2):7.

26. Wilton J, Kain T, Fowler S, Hart TA, Grennan T, Maxwell J, et al. Use of an HIV-risk screening tool to identify optimal candidates for PrEP scale-up among men who have sex with men in Toronto, Canada: disconnect between objective and subjective HIV risk. J Int AIDS Soc. 2016;19(1):20777

27. Gallagher T, Link L, Ramos M, Bottger E, Aberg J, Daskalakis D. Selfperception of HIV risk and candidacy for pre-exposure prophylaxis among men who have sex with men testing for HIV at commercial sex venues in New York City. LGBT Health. 2014;1(3):218-24.

28. Golub SA. Tensions between the epidemiology and psychology of HIV risk: implications for pre-exposure prophylaxis. AIDS Behav. 2014;18(9):1686-93.

29. MacKellar DA, Valleroy LA, Secura GM, Behel S, Bingham T, Celentano DD, et al. Perceptions of lifetime risk and actual risk for acquiring HIV among young men who have sex with men. AIDS Behav. 2007:11(2):263-70.

30. MacKellar DA, Valleroy LA, Secura GM, Behel S, Bingham T, Celentano DD, et al. Unrecognized HIV infection, risk behaviors, and perceptions of risk among Young men who have sex with men: opportunities for advancing 
HIV prevention in the third decade of HIV/AIDS. J Acquir Immune Defic Syndr. 2005;38(5):603-14.

31. Goedel WC, Halkitis PN, Greene RE, Hickson DA, Duncan DT. HIV risk behaviors, perceptions, and testing and preexposure prophylaxis (PrEP) awareness/use in grindr-using men who have sex with men in Atlanta, Georgia. J Assoc Nurses AIDS Care. 2016;27(2):133-42.

32. Newcomb ME, Mustanski B. Cognitive influences on sexual risk and risk appraisals in men who have sex with men. Health Psychol. 2014;33(7):690-8.

33. Gomes RR, Batista JR, Ceccato M, Kerr LRFS, Guimarães MDC. HIV/AIDS knowledge among men who have sex with men: applying the item response theory. Rev Saúde Pública. 2014;48(2):206-15.

34. Guimarães MDC, Magno L, Ceccato M, Gomes RR, Leal AF, Knauth DR, et al. HIV/AIDS knowledge among MSM in Brazil: a challenge for public policies. Rev Bras Epidemiol. 2019;22(suppl 1):e190005.

35. Chan PA, Glynn TR, Oldenburg CE, Montgomery MC, Robinette AE, Almonte A, et al. Implementation of preexposure prophylaxis for human immunodeficiency virus prevention among men who have sex with men at a new england sexually transmitted diseases clinic. Sex Transm Dis. 2016; 43(11):717-23.

36. Feinstein BA, Moran KO, Newcomb ME, Mustanski B. Differences in HIV risk behaviors between self-identified gay and bisexual Young men who are HIV-negative. Arch Sex Behav. 2019;48(1):261-75.

37. Damacena GN, Szwarcwald CL, Motta LR, Kato SK, Adami A, Paganella MP. et al. A portrait of risk behavior towards HIV infection among Brazilian Army conscripts by geographic regions, 2016. Rev Bras Epidemiol. 2019;22(suppl 1):e190009.

38. Ludford KT, Vagenas $P$, Lama JR, Peinado J, Gonzales $P$, Leiva R, et al. Screening for drug and alcohol use disorders and their association with HIVrelated sexual risk behaviors among men who have sex with men in Peru. PLoS ONE. 2013;8(8):e69966 Grinsztejn BGJ, editor.

39. Stueve A, O'Donnell L, Duran R, San Doval A, Geier J. Community intervention trial for youth Study Team. Being high and taking sexual risks: findings from a multisite survey of urban young men who have sex with men. AIDS Educ Prev. 2002;14(6):482-95.

40. Mimiaga MJ, O'Cleirigh C, Biello KB, Robertson AM, Safren SA, Coates TJ, et al. The effect of psychosocial syndemic production on 4-year HIV incidence and risk behavior in a large cohort of sexually active men who have sex with men. J Acquir Immune Defic Syndr. 2015;68(3):329-36.

41. Laranjeira R. Brazil's market is unregulated. BMJ. 2007;335(7623):736.2-736.

42. Venturi G. Consumo de drogas, opinião pública e moralidade: motivações e argumentos baseados em uso. Tempo Soc. 2017;29(2):159.

43. Khawcharoenporn T, Mongkolkaewsub S, Naijitra C, Khonphiern W, Apisarnthanarak A, Phanuphak N. HIV risk, risk perception and uptake of HIV testing and counseling among youth men who have sex with men attending a gay sauna. AIDS Res Ther. 2019;16(1):13.

44. Lapinski MK, Rimal RN, Klein KA, Shulman HC. Risk perceptions of people living with HIV/AIDS: how similarity affects optimistic bias. J Health Psychol. 2009;14(2):251-7.

45. Huebner DM, Rebchook GM, Kegeles SM. A longitudinal study of the association between treatment optimism and sexual risk behavior in young adult gay and bisexual men. J Acquir Immune Defic Syndr. 2004;37(4):1514-9.

46. Stockman J, Schwarcz S, Butler L, de Jong B, Chen S, Delgado V, et al. HIV prevention fatigue among high-risk populations in San Francisco. J Acquir Immune Defic Syndr. 2004;35(4):432-4.

47. Sharma A, Kahle EM, Sullivan SP, Stephenson R. Birth cohort variations across functional knowledge of HIV prevention strategies, perceived risk, and HIV-associated behaviors among gay, bisexual, and other men who have sex with men in the United States. Am J Mens Health. 2018;12(6): 1824-34.

48. Warren EA, Paterson P, Schulz WS, Lees S, Eakle R, Stadler J, et al. Risk perception and the influence on uptake and use of biomedical prevention interventions for HIV in sub-Saharan Africa: a systematic literature review. PLoS ONE. 2018;13(6):e0198680 Hills RK, editor.

49. Stephenson R, White D, Darbes L, Hoff C, Sullivan P. HIV testing behaviors and perceptions of risk of HIV infection among MSM with Main partners. AIDS Behav. 2015;19(3):553-60.

50. Bavinton BR, Pinto AN, Phanuphak N, Grinsztejn B, Prestage GP, ZablotskaManos IB, et al. Viral suppression and HIV transmission in serodiscordant male couples: an international, prospective, observational, cohort study. Lancet HIV. 2018;5(8):e438-47.
51. Calabrese SK, Mayer KH. Providers should discuss $U=U$ with all patients living with HIV. Lancet HIV. 2019;6(4):e211-3.

52. Brasil, Ministério da Saúde. Protocolo clínico e diretrizes terapêuticas para atenção integral às pessoas com infecções sexualmente transmissíveis (IST). Brasilia: Ministério da Saúde; 2016. 121 p

53. Centers for Disease Control (CDC). Testing | HIV Basics | HIV/AIDS | CDC [Internet]. 2018. Available from: https://www.cdc.gov/hiv/basics/testing.html [cited 2019 Jul 9].

54. Golub SA, Gamarel KE. The impact of anticipated HIV stigma on delays in HIV testing behaviors: findings from a community-based sample of men who have sex with men and transgender women in New York City. AIDS Patient Care STDs. 2013;27(11):621-7.

55. Krueger EA, Chiu CJ, Menacho LA, Young SD. HIV testing among social media-using Peruvian men who have sex with men: correlates and social context. AIDS Care. 2016;28(10):1301-5.

56. The INSIGHT START Study Group. Initiation of antiretroviral therapy in early asymptomatic HIV infection. N Engl J Med. 2015;373(9):795-807.

57. Cohen MS, Chen YQ, McCauley M, Gamble T, Hosseinipour MC, Kumarasamy N, et al. Prevention of HIV-1 infection with early antiretroviral therapy. N Engl J Med. 2011;365(6):493-505.

58. Torres TS, Konda KA, Vega-Ramirez EH, Elorreaga-Reyes OA, Diaz-Sosa D, Pimenta C, et al. Willingness to use HIV self-testing among MSM from Brazil, Mexico, and Peru | CROI Conference. 2019. Available from: https://www. croiconference.org/sessions/willingness-use-hiv-self-testing-among-msmbrazil-mexico-and-peru [cited 2019 Jul 9].

59. Grinsztejn B, Hoagland B, Moreira RI, Kallas EG, Madruga JV, Goulart S, et al. Retention, engagement, and adherence to pre-exposure prophylaxis for men who have sex with men and transgender women in PrEP Brasil: 48 week results of a demonstration study. Lancet HIV. 2018;5(3):e136-45.

60. Magno L, Dourado I, Sutten Coats C, Wilhite D, da Silva LAV, Oni-Orisan O, et al. Knowledge and willingness to use pre-exposure prophylaxis among men who have sex with men in northeastern Brazil. Glob Public Health. 2019;14(8):1098-111.

61. Heerwegh D. Mode differences between face-to-face and web surveys: an experimental investigation of data quality and social desirability effects. Int J Public Opin Res. 2009;21(1):111-21.

62. Brasil, Ministério da Saúde. Protocolo Clínico e Diretrizes Terapêuticas para Profilaxia Pré-Exposição (PrEP) de Risco à Infecção pelo HIV [Internet]. 2018. Available from: http://www.aids.gov.br/pt-br/pub/2017/protocolo-clinico-ediretrizes-terapeuticas-para-profilaxia-pre-exposicao-prep-de-risco

63. World Health Organization (WHO). Guidance on oral pre-exposure prophylaxis (PrEP) for serodiscordant couples, men and transgender women who have sex with men at high risk of HIV Recommendations for use in the context of demonstration projects [Internet]. 2012. Available from: https://www.who.int/hiv/pub/guidance_prep/en/.

64. Morrison SA, Yoong D, Hart TA, MacPherson P, Bogoch I, Sivarajah V, et al. High prevalence of syndemic health problems in patients seeking postexposure prophylaxis for sexual exposures to HIV. PLoS One. 2018;13(5): e0197998.

\section{Publisher's Note}

Springer Nature remains neutral with regard to jurisdictional claims in published maps and institutional affiliations.

Ready to submit your research? Choose BMC and benefit from:

- fast, convenient online submission

- thorough peer review by experienced researchers in your field

- rapid publication on acceptance

- support for research data, including large and complex data types

- gold Open Access which fosters wider collaboration and increased citations

- maximum visibility for your research: over $100 \mathrm{M}$ website views per year

At $\mathrm{BMC}$, research is always in progress.

Learn more biomedcentral.com/submissions 